\title{
Effects of climate variables on the transmission of COVID-19: a systematic review of 62 ecological studies
}

\author{
Hu-Li Zheng ${ }^{1} \cdot$ Ze-Li Guo ${ }^{1} \cdot$ Mei-ling Wang ${ }^{1} \cdot$ Chuan Yang ${ }^{1} \cdot$ Shu-Yi An ${ }^{2} \cdot$ Wei Wu ${ }^{1}$ \\ Received: 1 June 2021 / Accepted: 7 August 2021 / Published online: 16 August 2021 \\ (C) The Author(s), under exclusive licence to Springer-Verlag GmbH Germany, part of Springer Nature 2021
}

\begin{abstract}
The new severe acute respiratory syndrome coronavirus 2 was initially discovered at the end of 2019 in Wuhan City in China and has caused one of the most serious global public health crises. A collection and analysis of studies related to the association between COVID-19 (coronavirus disease 2019) transmission and meteorological factors, such as humidity, is vital and indispensable for disease prevention and control. A comprehensive literature search using various databases, including Web of Science, PubMed, and Chinese National Knowledge Infrastructure, was systematically performed to identify eligible studies from Dec 2019 to Feb 1, 2021. We also established six criteria to screen the literature to obtain high-quality literature with consistent research purposes. This systematic review included a total of 62 publications. The study period ranged from 1 to 8 months, with 6 papers considering incubation, and the lag effect of climate factors on COVID-19 activity being taken into account in 22 studies. After quality assessment, no study was found to have a high risk of bias, 30 studies were scored as having moderate risks of bias, and 32 studies were classified as having low risks of bias. The certainty of evidence was also graded as being low. When considering the existing scientific evidence, higher temperatures may slow the progression of the COVID-19 epidemic. However, during the course of the epidemic, these climate variables alone could not account for most of the variability. Therefore, countries should focus more on health policies while also taking into account the influence of weather.
\end{abstract}

Keywords Climate variables $\cdot$ COVID-19 $\cdot$ Temperature $\cdot$ Humidity $\cdot$ Ultraviolet ray

\section{Introduction}

The current COVID-19 outbreak is a global pandemic caused by the novel coronavirus, which can result in severe acute respiratory syndrome coronavirus 2 and has affected more than 103 million people globally, including 206 countries, and has resulted in over 2 million deaths worldwide as of January 31, 2021 (Dong et al. 2020). The new pandemic has become one of the worst public health crises, arousing considerable concern throughout the world. The new virus is mainly transmitted when people are in close contact, often via small droplets that are produced by coughing, sneezing,

Responsible editor: Lotfi Aleya

Wei Wu

wuwei@cmu.edu.cn

1 Department of Epidemiology, School of Public Health, China Medical University, Shenyang, Liaoning, China

2 Liaoning Provincial Centers for Disease Control and Prevention, Shenyang, Liaoning, China and talking, which exposes the virus to the external environment. Usually, instead of remaining in the air for a long period of time, droplets are peculiarly prone to falling to the ground or surfaces (Srivastava 2021). Its mechanism of rapid transmission and virological characteristics have not been fully explored and understood, but we know that, historically, many viruses have possessed different stabilities in different environments and that some infectious diseases have changed with the weather. For example, Middle East respiratory syndrome coronavirus was observed to be more stable under low temperature or low humidity conditions and could still be recovered after $48 \mathrm{~h}$ in the laboratory (van Doremalen et al. 2013). Historically, human-to-human transmissions of coronavirus and positive viscous infectious diseases have been mostly reported in subtropical monsoon climates or in winter and spring festivals in the Northern Hemisphere, whereas Flavivirus infectious diseases have been mostly detected in tropical regions, as well as in hot and rainy summers and autumns (Wang et al. 2020b). Additionally, the transmission of rotavirus has been shown to peak in December or January in the southwestern USA, but it has also been shown to peak in April 
and May in the Northeast (Mo 2020). At present, some scholars have found that COVID-19 is sensitive to high temperature and humidity conditions in the laboratory. For example, Casanova et al. have found that there was greater survival at low temperatures and low relative humidity for SARSCoV-2 under laboratory conditions (Casanova et al. 2010). In cell cultures, the new coronavirus was observed to be highly stable at $4{ }^{\circ} \mathrm{C}$. Moreover, its survival was found to be related to the concentration of the virus, and the high concentration of the virus could survive for 7 days at $22.5^{\circ} \mathrm{C}$, whereas the virus only remained completely alive for 1 day at $37^{\circ} \mathrm{C}$ (Cui et al. 2021). This in vitro study showed that SARS-CoV-2 obtained from a COVID-19 patient could be rapidly inactivated via irradiation with a deep ultraviolet light-emitting diode (DUV-LED) of $280 \pm 5 \mathrm{~nm}$ wavelength (Inagaki et al. 2020). These results suggest that the epidemic of COVID-19 may be associated with meteorological variables, such as ultraviolet light and temperature.

Therefore, the exploration of the climate factors affecting the spread of the new coronavirus has become one of the key research issues in academic circles. Various methods, including mathematical models and machine learning algorithms, have been used to identify the epidemiologic relationship between COVID-19 prevalence and weather in different temporal and spatial dimensions. In this systematic review, we comprehensively collected and analyzed the studies involved in the epidemic status of COVID-19 and climate to summarize the methods of ecological studies and the results regarding the association between weather variables and COVID-19 incidence, which could be useful in better predicting the incidence of COVID-19.

\section{Materials and methods}

\section{Study selection}

A systematic search in Web of Science, PubMed (www. ncbi.nlm.nih.gov/pubmed), and Chinese National Knowledge Infrastructure (www.cnki.net) was conducted to collect publications concerning the correlation between COVID-19 incidence and weather throughout the world. Data that ranged from the start of the pandemic to Feb 1, 2021, were retrieved by means of the keywords "COVID-19" and "wind" or "humidity" or "temperature" or "rainfall" or "precipitation" or "UV" or "weather" or "climate" or "seasonality" in both English and Chinese. Titles and abstracts were scanned for relevance, and further relevant studies were identified from the references. The literature retroactive method was also used to extend the literature search. The last search was performed on Feb 1, 2021.

\section{Inclusion and exclusion criteria}

All of the identified studies were subjected to the following six self-established criteria to ensure consistency with the research objectives: (i) new daily, weekly, or monthly confirmed cases of COVID-19 (or other incidence and transmission index that could describe the dynamics of disease) were presented; (ii) meteorological indexes were presented; (iii) the underlying geographical scale information, research period, and temporal data aggregation unit were presented; (iv) the statistical analysis methods that had been used and the results were clearly presented; (v) studies from peer-reviewed dissertations or journals; and (vi) for the included studies, the time range of the data was more than sixty consecutive days, except for the studies concerning spread and decay durations; however, the duration of the studies about China only required more than 30 days. Additionally, the epidemic in China has been generally controlled much better than in other countries. Therefore, epidemiological studies that only provided COVID-19 mortality or admission rate data or studies that did not clearly describe methods or weather indexes were removed, and reviews and comment were also removed. If the studies were repeatedly published, then a dissertation with more detailed information was selected.

\section{Data extraction}

The following information was extracted from each included study, which was based on our self-designed information extraction list: first author and publication year, region and period, the type of COVID-19 data, climate indexes (with the lag time considered), temporal data aggregation unit (monthly, weekly, or daily), the statistical method that was used, major results regarding the correlation between climate and COVID19 activity, and limitations.

To improve the reliability, we adopted the standard Cochrane methods (Cumpston et al. 2019). Two review authors (ZHL and GZL) independently screened for potentially eligible studies by glancing over the titles, abstracts, and full texts; additionally, they created a shortlist and determined final eligibility by using the predetermined inclusion and exclusion criteria. Subsequently, two review authors (ZHL and GZL) independently extracted data from the included studies and entered the data into the well-established data extraction form. We resolved any disagreement with the help of a third review author (WW) who acted as an arbiter. Included publications were considered to be qualified only when the data were extracted and double-checked.

\section{Risk assessment of study bias}

In consideration of the PRISMA statement (Moher et al. 2009), the modified criteria from BioMed Central (Wang 
et al. 2018), the Joanna Briggs Institute (JBI) Critical Appraisal Checklist tool (Mecenas et al. 2020), and the systematic review by Bai et al. (2019), we used the self-designed risk assessment item list (Table S2) to assess the qualities of the included ecological studies. The risks of bias in the included ecological studies were evaluated with twelve risk-biased items that were divided into external validity (items 1 to 3 ) and internal validity (items 4 to 12), which assessed the domain of selection and the domain of measurement bias and interpretation or extrapolation bias, respectively. For each item, the study was classified as "Yes" or "No", which indicates "Low risk" or "High risk," respectively. Two investigators (ZHL and GZL) negotiated with the help of the principal investigator (WW) and completed the quality assessment.

The resulting interpretation of the risk assessment, which was similar to the previously established standards (Zhang et al. 2019), was as follows: studies with a "No" score $\leq 30 \%$ (1-3) were classified as being low risk, studies with a "No" score $30-60 \%$ (4-7) were classified as being moderate risk, and studies with a "No" score $>60 \%(8-12)$ were classified as being high risk.

\section{Certainty of evidence}

The included studies were given a narrative GRADE related to the outcomes and effects of climate variables on the transmission of COVID-19, which was evaluated in this review according to the GRADE guidelines (Balshem et al. 2011). The guidelines consider five aspects for rating the following levels of evidence: design, risk of bias, consistency, directness, and precision of the studies. The levels of evidence were classified as being high, moderate, low, or very low. The outcomes that were evaluated were "association between weather (solar radiation, temperature, humidity, and other climate factors) and transmission of COVID-19."

\section{Results}

\section{Study selection}

The initial searches identified 346 articles: 102 articles from Web of Science, 235 articles from PubMed, and 9 articles from CNKI. A total of 215 articles that were related to the objective and published online between Dec 2019 and Feb 1, 2021, were identified, including 206 publications in English and 9 publications in Chinese. After reading the titles, abstracts, and full-texts of these articles, only 62 publications (61 in English and 1 in Chinese) were ultimately included in this systematic review and selected for qualitative assessments of bias risk. The literature selection process is shown in Fig. 1.

\section{Characteristics of the included studies}

The characteristics of the included studies are presented in Table 1. All of the studies were retrospective observational studies analyzing the association between climate variables with the transmission of COVID-19.

Of these studies, seven studies were global analyses of weather variables - three studies assessed the global distributions at the continent, country, or region level, two studies evaluated the associations in 65 countries and 67 countries, one study selected analyses of 47 affected countries on six continents, and the remaining study analyzed 127 "Belt and Road" countries (not including China). The remaining fifty-five studies were at the province, city, site, county, or community level, including six continents (except for Antarctica). Thirty-three studies focused on the correlation between weather and COVID-19 transmission in Asia: thirteen studies for selected cities or provinces of China but only eight studies from China, nine studies for India, two studies for Pakistan, two studies for Bangladesh, and seven studies for Jordan, Korea, Japan, Singapore, Jakarta of Indonesia, 9 Asian cities, and 4 South Asian countries, respectively. Five studies focused on the correlation in North America, with two studies for the USA and three studies for Ontario of Canada, Canadian, and Victoria of Mexico regions. Seven studies focused on the association in Europe for 4 European countries, Spanish, the original EU-15 countries, the Russian Federation in Europe, 10 European countries, Oslo of Norway, and Italy. Three studies were based in Africa, including Ghana, Lagos of Nigeria, and 16 countries of Africa. Only one study was based in South America (São Paulo in Brazil). Finally, there are six remaining studies: one study that intentionally selected 11 of the most infected cities worldwide and 3 countries, one comparative study concerning China, England, Germany, and Japan, one study selecting the 10 hottest and 10 coldest countries, one study for the top 20 countries with confirmed cases, one study analyzing 9 locations in four continents, and the final study selecting 428 Chinese cities and districts, 18 Italian provinces, and 13 other countries.

All of the included studies focused on many weather factors, including temperature, dew point, temperature range, solar radiation, sunshine duration, humidity, pressure, evaporation, precipitation, wind, and visibility. Lagged effects were considered in 22 studies. The incubation period was considered in 6 studies. Moreover, only one study provided a positive control and a negative control. To avoid potential differences in the absolute number of medical records among the districts (due to different criteria and regulations), a normalization test was conducted (Rashed et al. 2020). Additionally, time series data 
Fig. 1 Flow diagram of study selection.

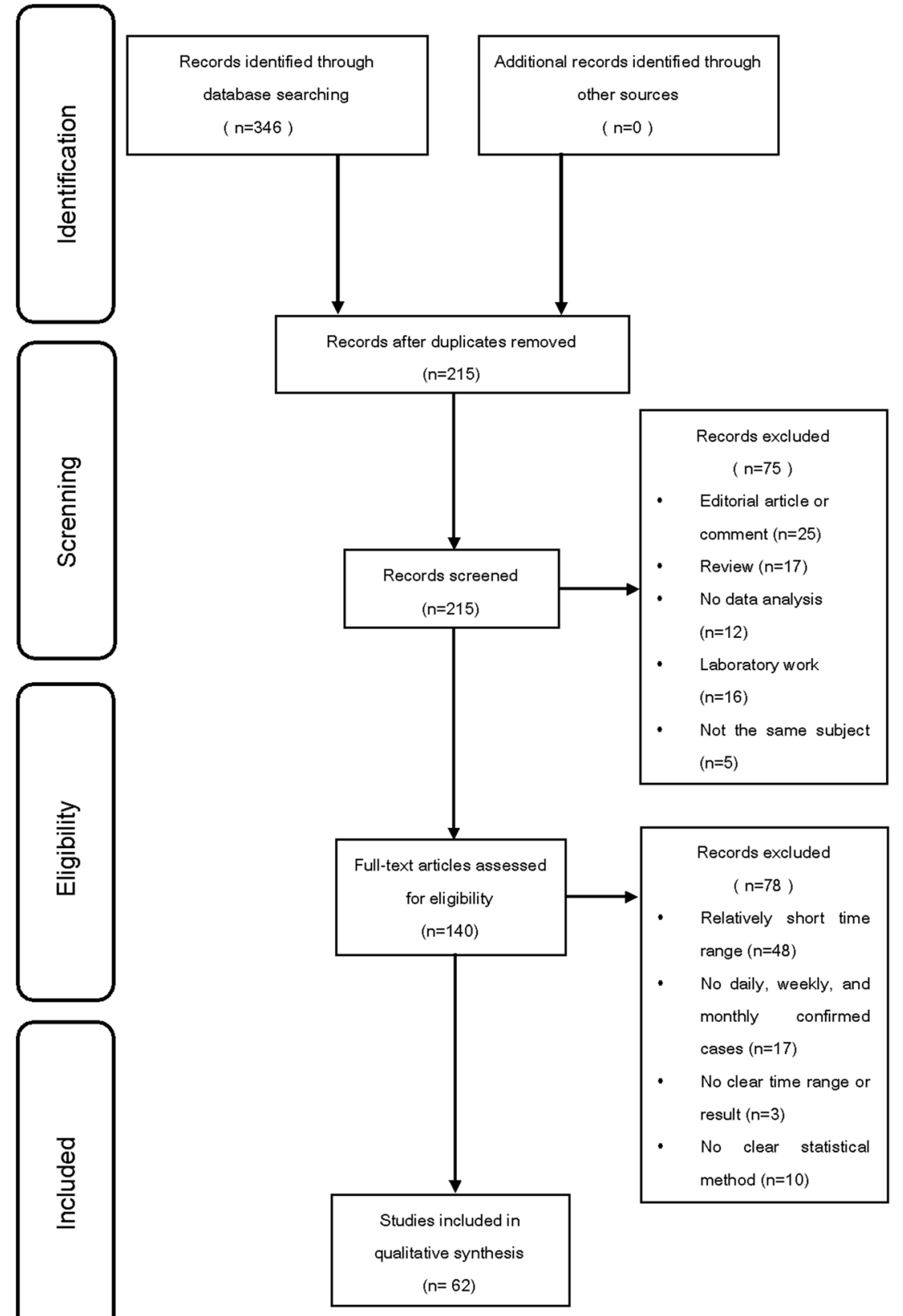

or COVID-19 data were smoothed by using a sliding window in some studies.

\section{Correlations between climate variables and the transmission of COVID-19}

In the 62 included studies, the correlations between major climate variables and the transmission of COVID-19 are presented in Table 2.

Temperature, humidity, and wind were the most popular factors to study. Although the effects of climate variables on COVID-19 activity varied among different country populations, time units, and analytical methods, there were also similar results in the included studies, and especially most of the literature showed that higher temperatures may have largely influenced the spread of coronavirus and suppressed the pandemic. Among the included studies, fifty-eight studies explored the relationship between temperature and COVID-19 transmission, but only one study investigated the heat index, which was found to be positively correlated with the daily basic reproductive number $\left(\mathrm{R}_{0}\right)$, growth rate, and doubling time (Adnan et al. 2021). Additionally, another study adopted the mean equivalent temperature and found it to be a noninfluential factor on COVID-19 activity (Jamshidi et al. 2020). 


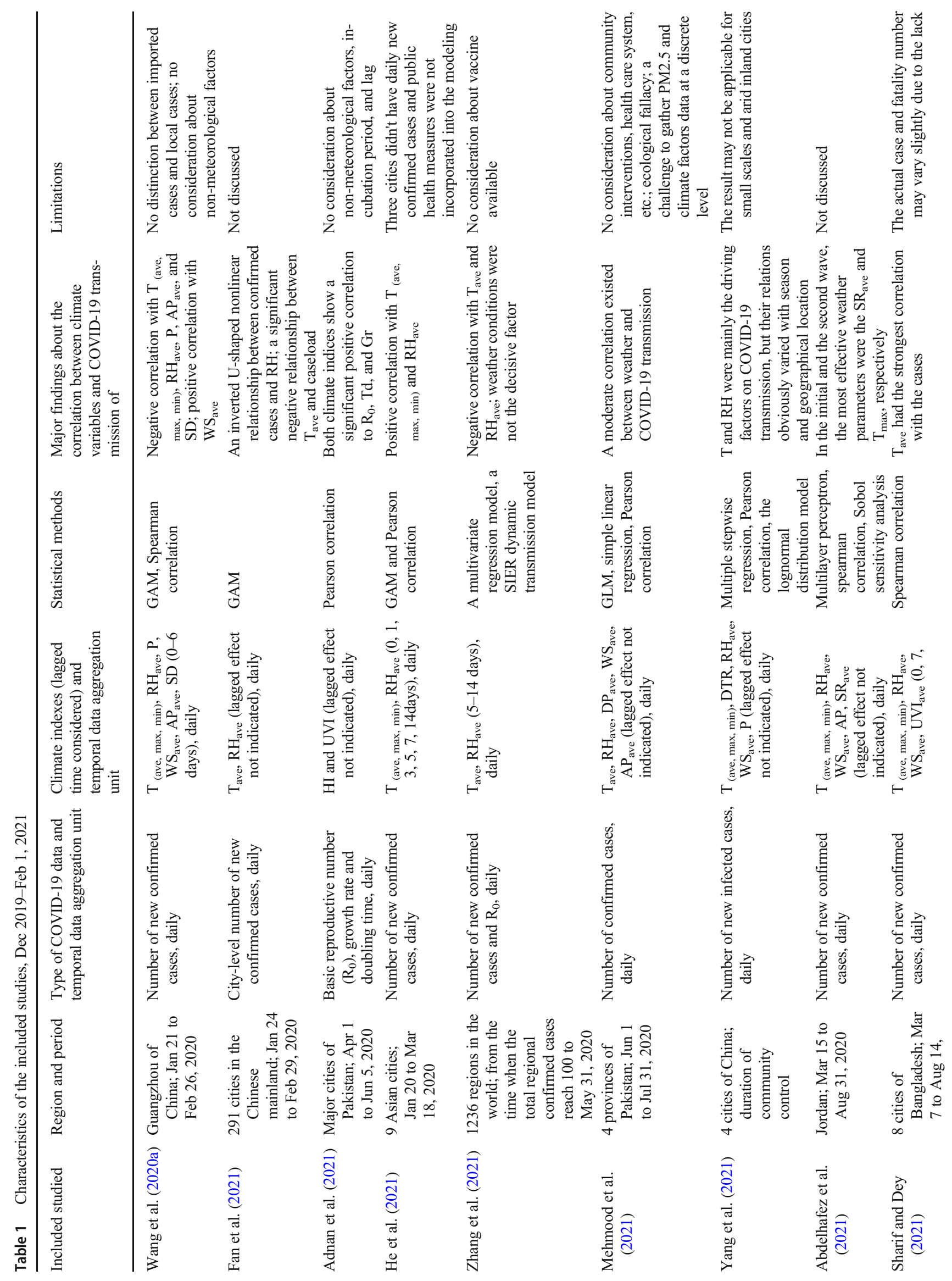




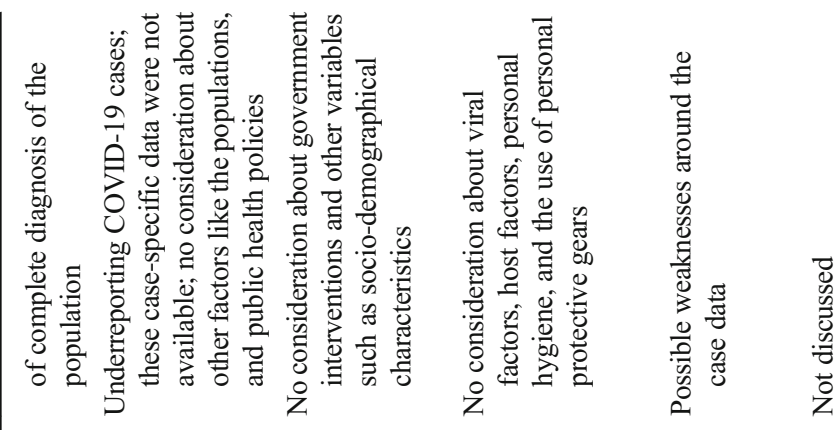

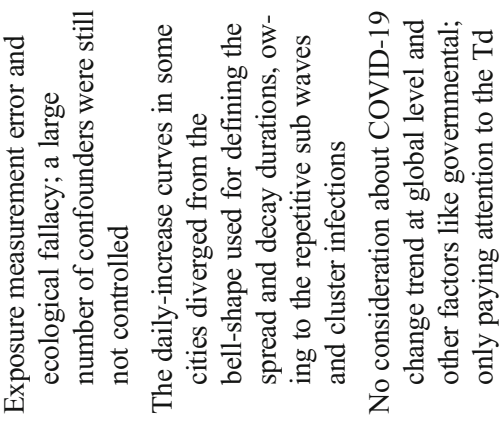

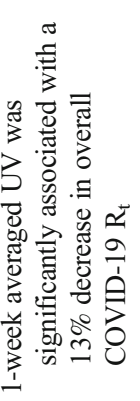

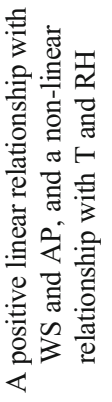

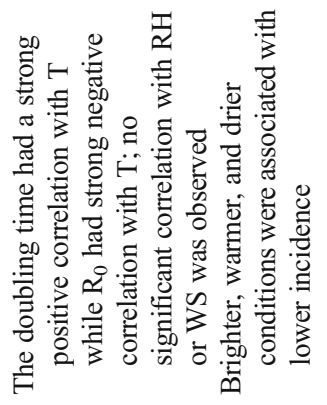

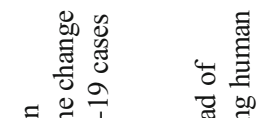

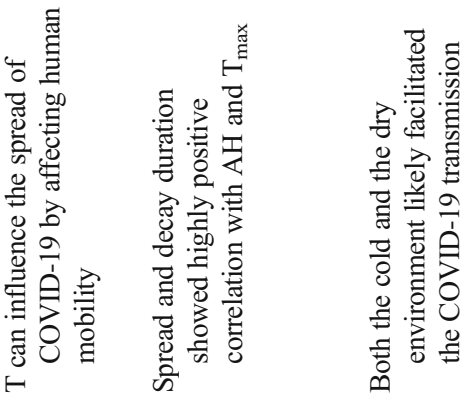

.气

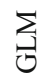

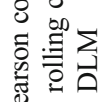

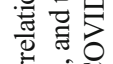

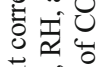

苞苛

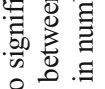

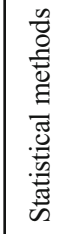

ช. . .

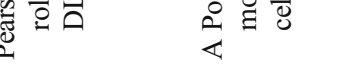

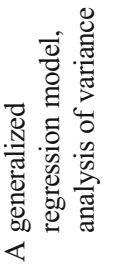

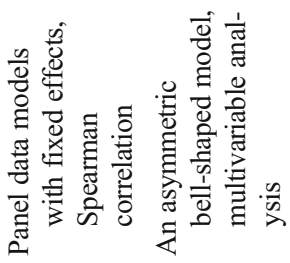

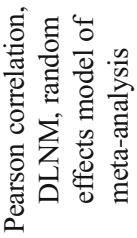

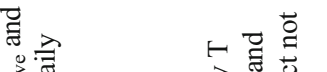

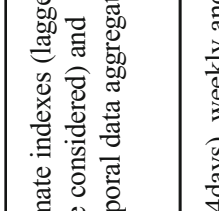

要

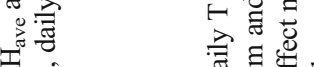

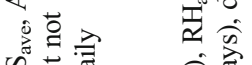

窟

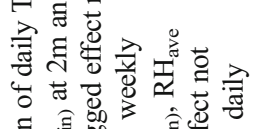

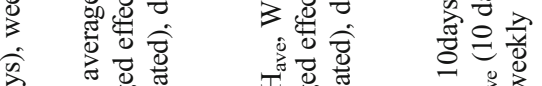

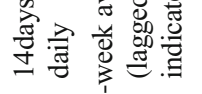

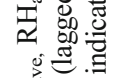

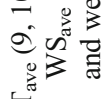

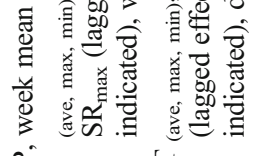

高

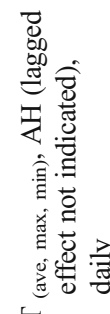

यद

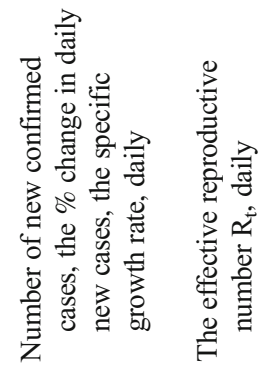

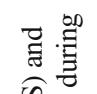

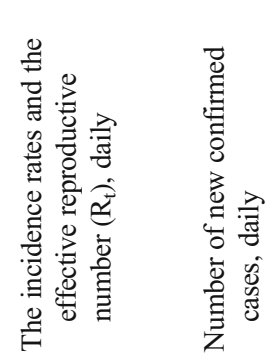

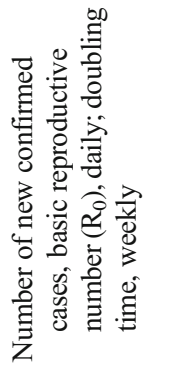

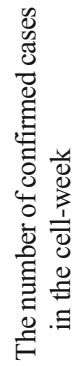

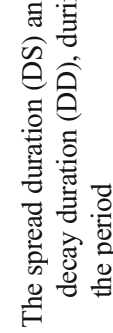

ซึ๊

䒿志

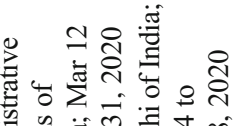

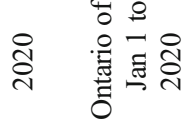

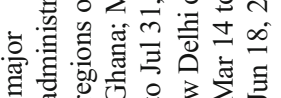

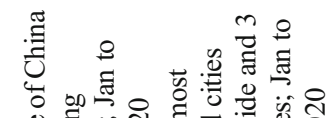

on

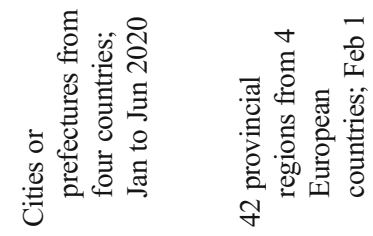

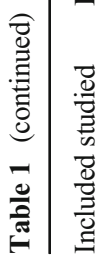

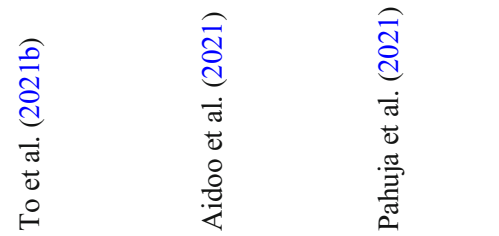

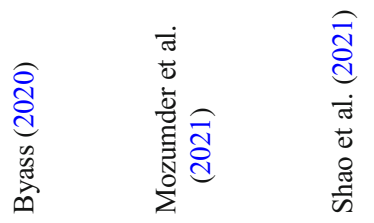

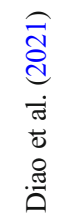

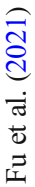

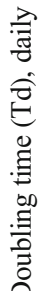




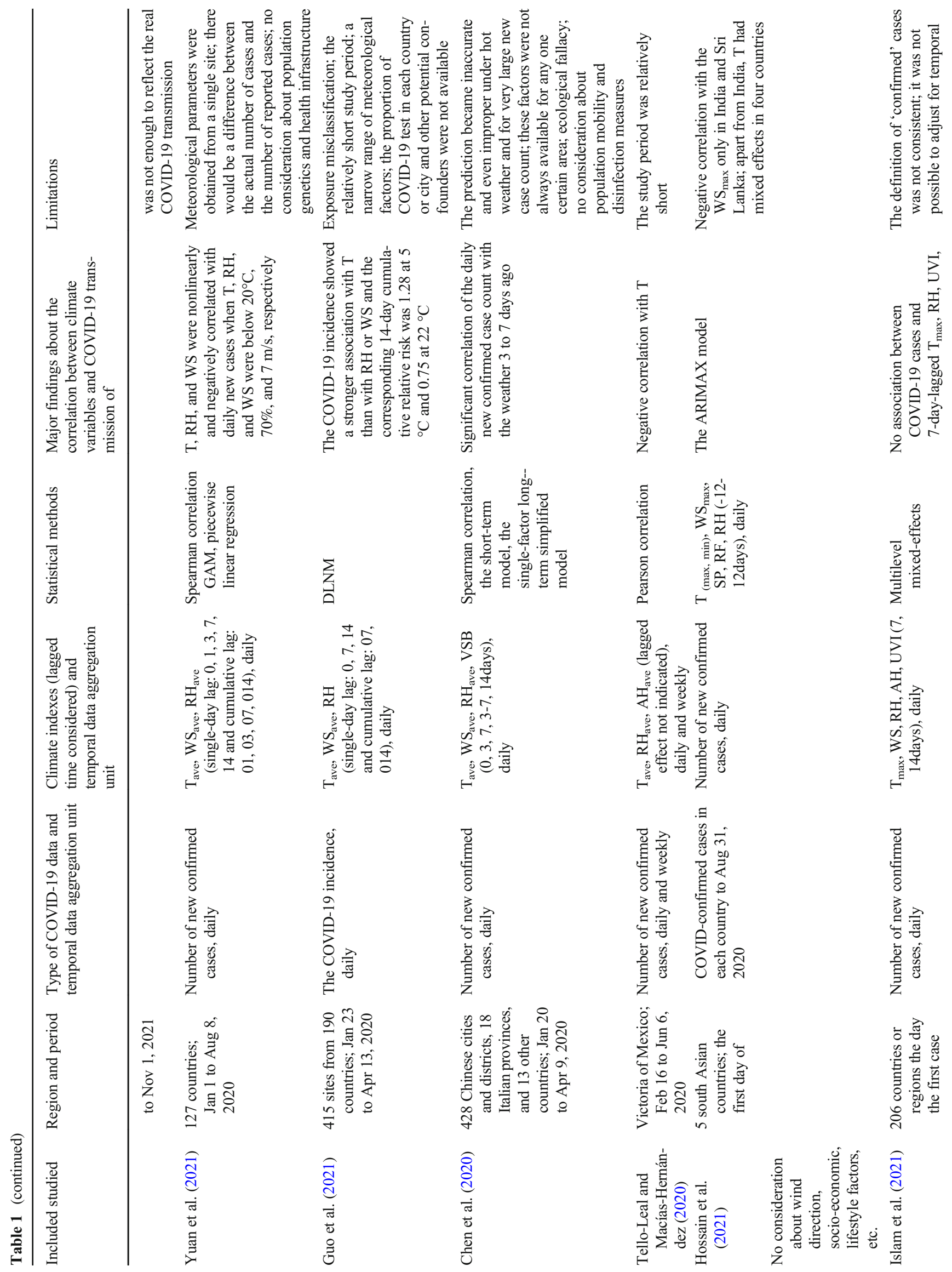




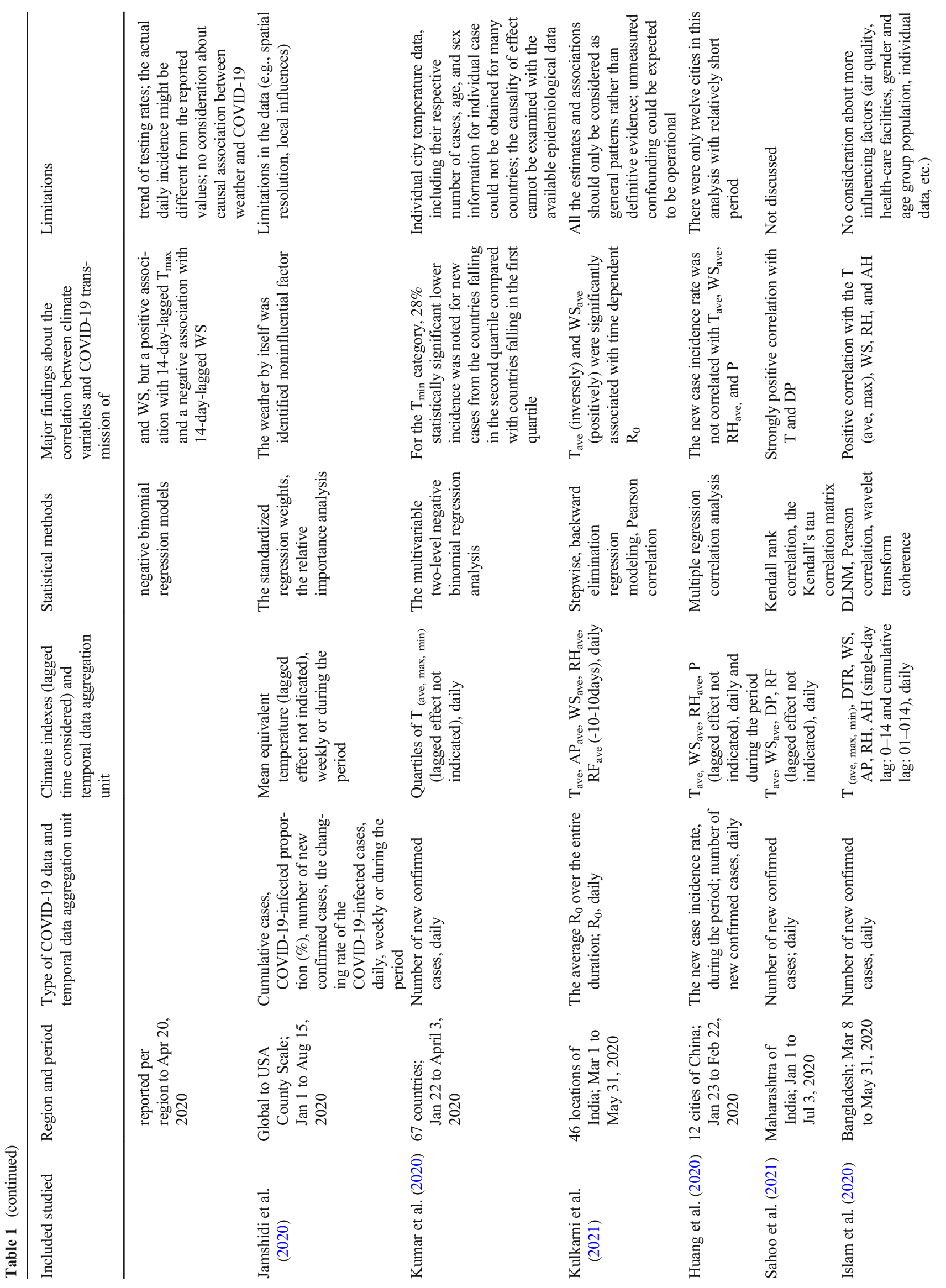




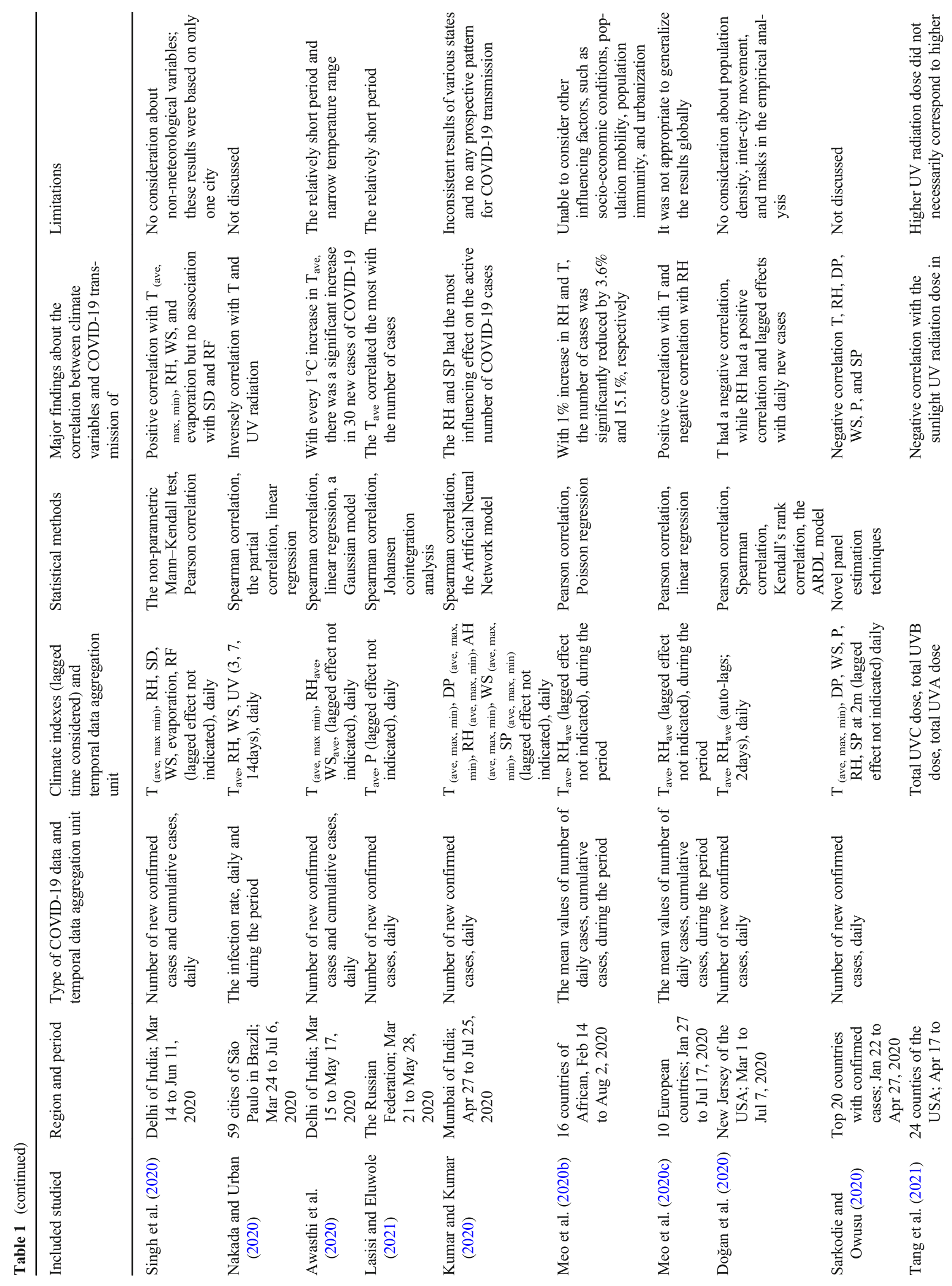




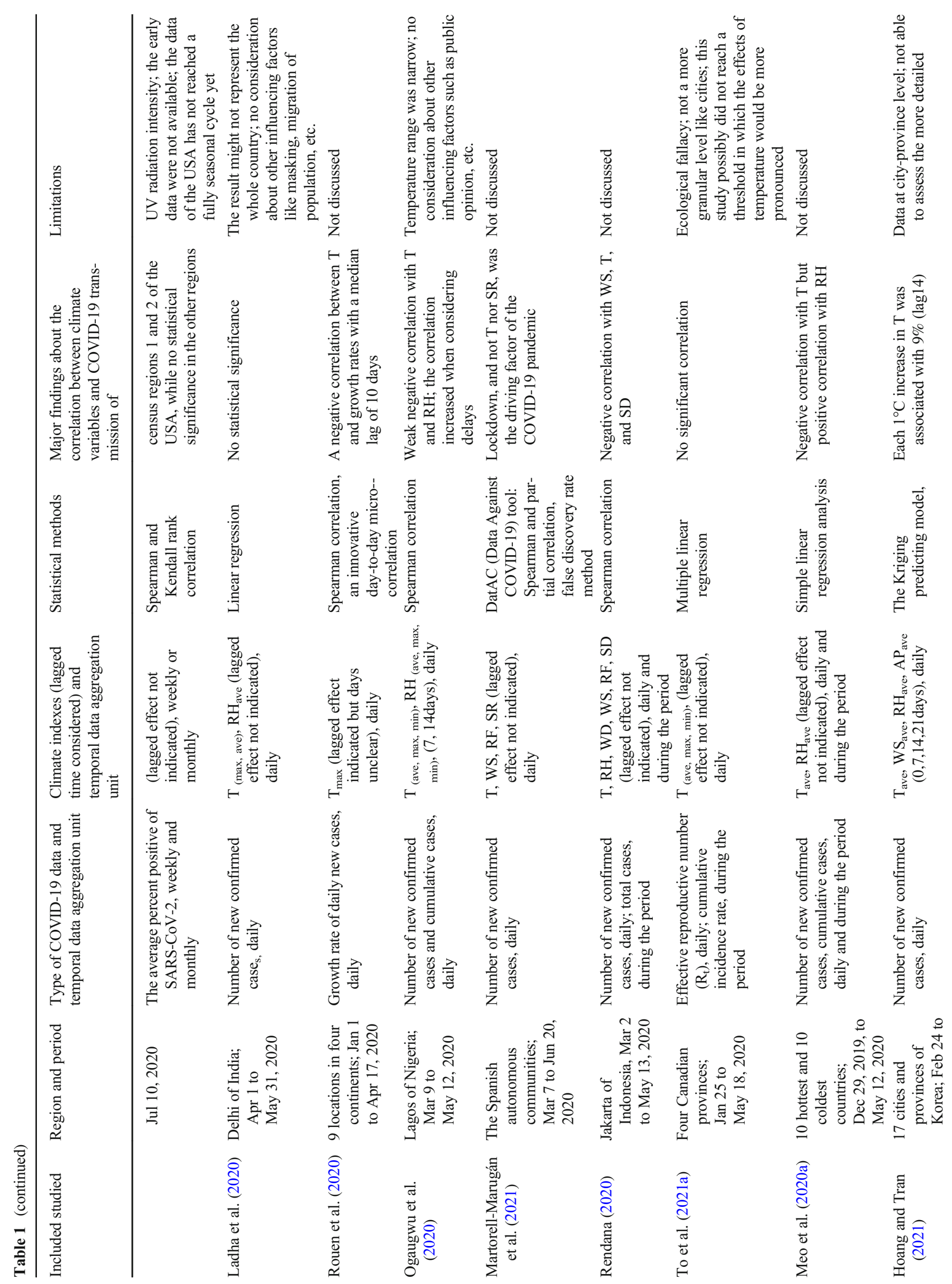




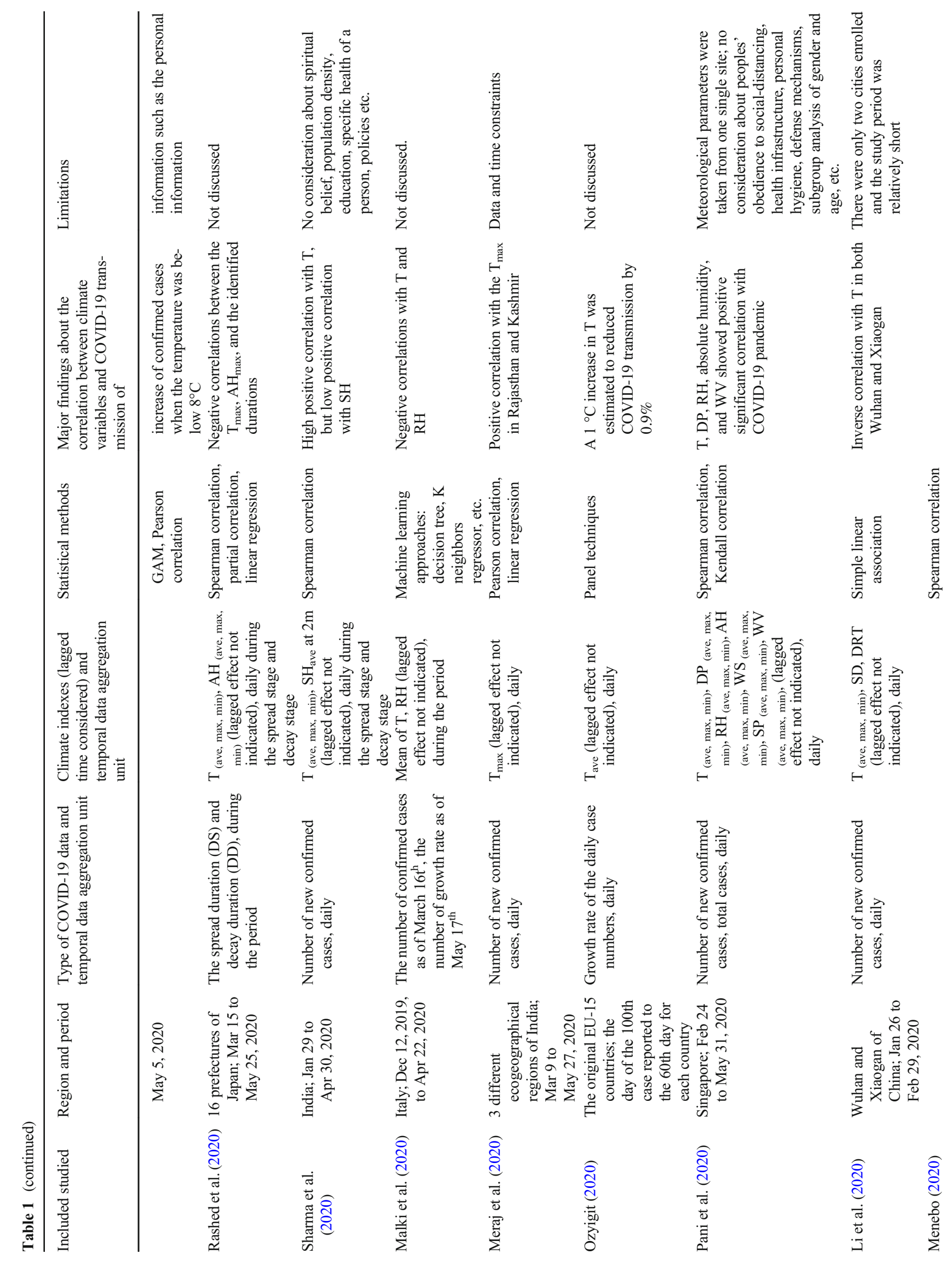




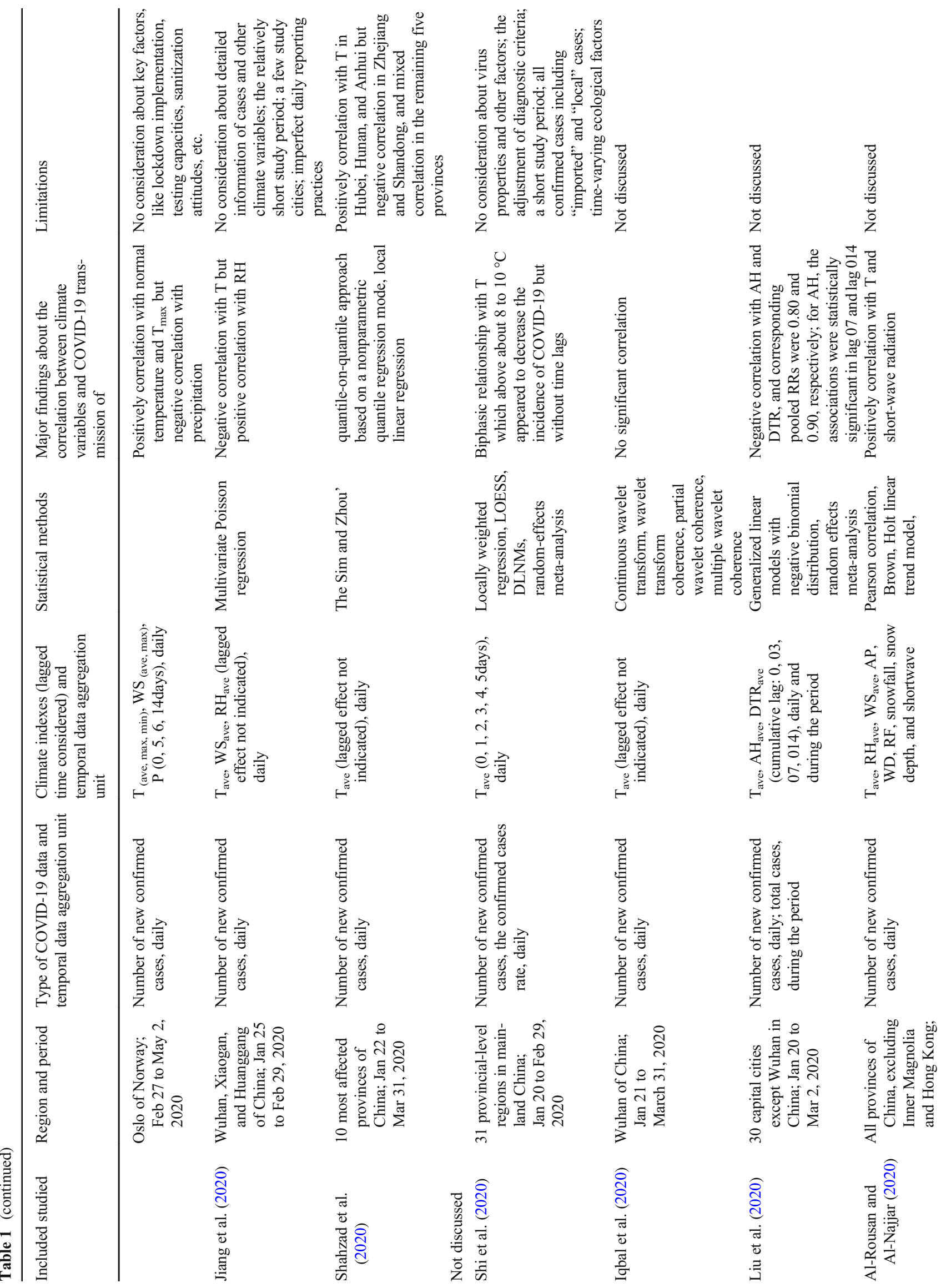


In thirty-seven studies that analyzed relative humidity, fourteen studies did not observe any significant correlations, which was a result that we could not ignore. In addition, another paper included the specific humidity and indicated the existence of a low positive correlation between confirmed cases of COVID-19 and specific humidity. Among twentyeight studies that analyzed wind speed, only two studies included wind direction, with one study showing that wind direction affected the number of COVID-19 cases (based on wind rose analysis), and the other study indicating that wind direction and wind speed produced minimal effects on the number of confirmed cases in $37.9 \%$ and $27.5 \%$ of the provinces, respectively, in China. When regarding humidity and wind, we cannot provide a specific conclusion through Table 1.

Similarly, it is not clear how sunlight, pressure, and precipitation were related to COVID-19 activity. In fact, precipitation includes rainfall and snowfall. Only one paper included rainfall, snowfall, and snow depth with rainfall and snow depth imparting minimal effects on the number of confirmed cases in $6 \%$ and $24.1 \%$ of the provinces, respectively, but no correlation being observed between snowfall rate and the number of confirmed cases in all of the Chinese provinces (Al-Rousan and Al-Najjar 2020). Many coronaviruses are sensitive to ultraviolet light under laboratory conditions, but the effect of ultraviolet light on COVID-19 was undefined at the macrolevel based on the results that $28.5 \%$ of the studies about sunlight found no correlation, and the remaining studies were also not relatively consistent. Furthermore, evaporation is not presented in Table 2. Only two studies analyzed evaporation, and both studies showed a positive relationship between confirmed cases and water vapor.

\section{Synthesis of results}

We did not perform a meta-analysis because of the heterogeneity of the modeling methods, locations, meteorological indicators, and data processing. Additionally, differing policies, abilities in resisting the disease, test standards, test ranges, and units of measure did not support meaningful comparisons. Hence, only simple and descriptive comparisons and summaries were conducted, beyond the risk of bias and the narrative GRADE of evidence of the results.

\section{Results of risk assessment and certainty of evidence}

The PRISMA checklist is provided in Table S1, and the risk bias and assessment results are provided in Table S2. The questions that received more "No" answers indicated the existence of study limitations. Among all of the included studies, 32 studies had a low risk of study bias, and 30 studies had a moderate risk of study bias. For the question of "Were potential confounding factors identified?", only four studies 
Table 2 Correlations between major climate variables and the transmission of COVID-19

\begin{tabular}{lllllll}
\hline Climate variables & Positive & Negative & Mixed & None & Total \\
\hline Temperature & T & 15 & 30 & 7 & 6 & 58 \\
& DP & 2 & 1 & 1 & 1 & 5 \\
& DRT & 0 & 2 & 0 & 3 & 5 \\
Humidity & RH & 8 & 9 & 6 & 14 & 37 \\
& AH & 3 & 4 & 0 & 2 & 9 \\
Sunlight & SD & 0 & 2 & 0 & 2 & 4 \\
& UVI & 1 & 2 & 0 & 1 & 4 \\
& UV & 1 & 2 & 0 & 0 & 3 \\
Wind speed & SR & 1 & 1 & 0 & 1 & 3 \\
Pressure & AP & 1 & 3 & 2 & 8 & 28 \\
& SP & 0 & 3 & 0 & 1 & 8 \\
Precipitation & & 1 & 3 & 0 & 3 & 7 \\
Rainfall & & 1 & 5 & 1 & 0 & 7 \\
\hline
\end{tabular}

Abbreviations: $T$ air temperature, $D P$ dew point, $D T R$ daily temperature range, $R H$ relative humidity, $A H$ absolute humidity, $S D$ sunshine duration, $U V I$ ultraviolet index, $U V$ ultraviolet, $S R$ solar radiation, $A P$ air pressure, $S P$ surface pressure

provided "Yes" answers (Islam et al. 2021; Sarkodie and Owusu 2020; Shao et al. 2021; Xie and Zhu 2020). For the question of "Were strategies to deal with confounding factors stated?", only three studies provided "Yes" answers (Islam et al. 2021; Shao et al. 2021; Xie and Zhu 2020).

The evaluation of the certainty of the evidence according to GRADE is described in Table 3. The level of certainty of the evaluated outcomes ("Association between weather variables and transmission of COVID-19") was classified as "low" in this systematic review.

\section{Discussion}

All of the included studies varied in times, countries, populations, data sources, data processing methods, models, controlling methods, independent variables, and dependent variables, thus leading to different results. This review did not consider COVID-19 mortality, recovery rate, and hospitalization rate, among other factors. The factors influencing these indicators can be more complex, and these indicators cannot clearly describe the prevalence of COVID-19 on a macrolevel. In addition, the included study periods must be longer than 2 months in order to observe a substantial change in the variables (to some extent).

\section{Variable selection}

For confirmed cases, little distinction was made between local and imported cases in all of the included studies, but Meyer A used daily local cases of COVID-19 (Meyer et al. 2020). When regarding the choice of outcome variables, the fortyeight selected studies only focused on the incidence rate, the number of new cases, or their proportions, but a small number of studies focused on the case growth rate, the changing rate, or infectivity of the novel coronavirus. Only three studies analyzed the effective reproductive numbers, four studies analyzed the basic reproductive numbers, six studies researched the growth rates, and three studies focused on the doubling times. In addition, two studies focused on the spread duration and decay duration, which could also describe the acceleration of the epidemic.

\section{Influencing factors}

There were many possible non-meteorological factors, such as governmental interventions, social contact, population mobility, and coverage rate of COVID-19, that could influence the correlation analysis between meteorological factors and COVID-19 spread. He et al. considered city level and public health measures as being controlling factors in the linear regression (He et al. 2021). Moreover, Zhang et al. included a lockdown variable to explain government intervention in local and cross-regional COVID-19 transmission (Zhang et al. 2021). Panel data models with fixed effects were used to identify the links between daily mean temperature, human

Table 3 Narrative GRADE evidence profile table

\begin{tabular}{|c|c|c|}
\hline Outcomes & Impact & $\begin{array}{l}\text { Certainty of the } \\
\text { evidence (GRADE) }\end{array}$ \\
\hline $\begin{array}{l}\text { Association between weather variables } \\
\text { and transmission of COVID-19 }\end{array}$ & $\begin{array}{l}\text { Among the sixty-two articles evaluated, nine only used Spearman, Pearson correlation, } \\
\text { or Kendall rank correlation to explore the association without considering other } \\
\text { influencing factors. Other articles included different times and countries. The asso- } \\
\text { ciations varied with different populations, research periods, sites, lag days, and } \\
\text { models even in the same article for the same variable. The effects of weather vari- } \\
\text { ables on COVID-19 transmission might be positive, negative, nonlinear, bilateral, or } \\
\text { irrelevant }\end{array}$ & Low \\
\hline
\end{tabular}


mobility, and transmission rate s(Shao et al. 2021). Additionally, Ladha et al. added the number of COVID-19 tests into the linear regression (Ladha et al. 2020). Fu et al. entered the government response index and other factors into the distributed lag nonlinear models as independent variables (Fu et al. 2021). However, only four studies identified potential confounding factors and conducted strategies to address the stated confounding factors, such as incorporations into the models and inclusions of dew point, cloud cover, precipitation, relative humidity, air pressure, or wind speed for the same period. The hypothesized associations between climatic variables and COVID-19 may change or not be maintained when a range of potential confounding variables are taken into account. It is strange that many studies regarded public opinion, gene mutation, social isolation, universal masking, and other factors as being confounding factors, but this systematic review does not agree with this perception, and we believe that only those factors meeting the definition of confounders are confounding factors (Valente et al. 2017).

Due to the confinement and reduction of socioeconomic activities caused by the pandemic, the air quality in Victoria, Mexico, has improved. Moreover, temperature was moderately to very strongly negatively correlated with all of the air pollution variables, and $\mathrm{PM}_{10}$ and $\mathrm{PM}_{2.5}$ possessed significant correlations with the cases (Tello-Leal and Macías-Hernández 2020). Hence, we speculated that air quality factors may be confounding factors. Geographic factors, such as elevation, are highly associated with the weather type and can indirectly affect air pressure (Zhang et al. 2021). Furthermore, the sunlight UV radiation dose varies with latitude and season (Tang et al. 2021), but no statistically significant association was found between any geographic characteristic and the $\mathrm{R}_{0}$ in India (Kulkarni et al. 2021). Therefore, the question as to whether latitude and longitude are confounding factors requires further study.

Another important issue is the direct link between meteorological variables and collinearity problems. Fan et al. performed a multicollinearity test to verify the degree to which weather variables were related to each other and found that multicollinearity was not a primary issue (Fan et al. 2021). Instead of using average daily temperature, Byass adopted the averages of maximum and minimum daily temperatures as a single measure of temperature to avoid collinearity between maximum and minimum temperatures and solar radiation when constructing a multivariable regression model (Byass 2020). To solve the problem that temperature and UV index were highly correlated, two separate models were used to fit for the temperature and the UV index, respectively, and all of the other variables were kept identical (Islam et al. 2021). Some studies were concerned about the relationships between meteorological factors and provided the correlation coefficients. For example, Tello-Leal et al. demonstrated the Pearson correlation coefficient matrix for main variables by using a dataset of the last 4 weeks of the partial lockdown (Tello-Leal and Macías-Hernández 2020). Moreover, Rendana et al. provided the Spearman correlation coefficients between wind speed and other meteorological factors and found that wind speed was positively associated with rainfall and temperature, as well as the fact that the correlation may be influenced by seasonal characteristics (Rendana 2020; Thangariyal et al. 2020).

\section{Interpretation and understanding of the main results}

When considering the existing scientific evidence, higher temperatures could slow the progression of the COVID-19 epidemic to a certain extent because high temperatures may reduce the viability, survival, activation, and infectivity of the virus. Fifteen studies believed that low temperature was related to higher morbidity. The possible reason for this effect is that the activity of the crowd is more indoors and windows are usually closed, which may increase the frequency of contact between people when it is cold or windy outside. For other climate variables, their correlations with the epidemic can vary, and there is not a relatively consistent view, due to a small amount of literature. Hence, more studies are needed.

There is an issue that cannot be ignored-variable contributions. There are several studies considering this issue. Diao et al. used the threshold value of the VIF to differentiate between low and high contributions and found a higher population density resulted in longer spread and decay durations, whereas meteorological factors had little effect on the durations (Diao et al. 2021). Malki et al. ranked feature importance through a random forest feature selector algorithm and found that temperature and hours of sunlight were important features for infected cases of COVID-19 cases, and climate factors were more important than demographics, such as population, age, and urban percentage, when inspecting mortality (Malki et al. 2020). Kulkarni et al. estimated the proportional reduction in error by using an established approach to quantify the relative contribution of each covariate with the timedependent $R_{0}$ and found that the contributions of air temperature and wind speed to dampening the $\mathrm{R}_{0}$ estimate were 3-4 times weaker than that in the countrywide lockdown phases 2-4 (Kulkarni et al. 2021). Hence, governments should take necessary human mobility restrictions and precautionary measures and regard prevention and control of the epidemic as regular.

\section{Strengths and limitations}

The greatest strength of our systematic review was that all of the meteorological variables appearing in the included studies were contained, including temperature, humidity, wind, dew point, temperature range, solar radiation, sunshine duration, pressure, evaporation, precipitation, and visibility. In addition, 
we have provided reference information for global epidemic control and proposed new breakthrough directions for future research. However, we only searched three databases, which could result in biases. The identification of confounding variables, the control of collinearity problems, and the consideration of influential factors were also important limitations of this systematic review. Moreover, there was no consideration of detailed information of cases such as age, weight, personal health status, and other factors. The relatively longer study periods could avoid the bias caused by various ecological factors over time, and more proper processing methods should be explored. Lastly, days of lagging effects and incubation periods need to be distinguished, especially if we want to consider both factors. More investigation is required to address the stated limitations.

\section{Recommendations for future research}

In future research, it is better to solve the previously stated limitations as much as possible and to pay more attention to the weathers and not to popular demand. In addition, largescale multicenter studies may be able to avoid many biases and obtain more concrete results. The optimization of existing models and the addition of prediction models or spatialtemporal models at a more specific and proper level are also good choices. Another essential consideration for future research is vaccine popularization and patient personal information when exploring the correlation between climate factors and the transmission of COVID-19.

\section{Conclusion}

In summary, based on a low level of evidence and limited studies, these climate variables alone could not explain most of the variability in disease transmission, but higher temperatures could slow the progression of the COVID-19 epidemic (to a certain extent). It is certain that weather factors, especially temperature, humidity, wind speed, and ultraviolet light, could play an important role in the epidemic, but the contribution of meteorological factors is relatively small compared to factors like lockdown, social interaction, herd immunity, migration patterns, population density, personal hygiene, defense mechanisms, obedience of individuals to policies, and socio-economic level. Therefore, countries should focus more on health policies and vaccines while taking into account the influence of weather on outbreaks.

Supplementary Information The online version contains supplementary material available at https://doi.org/10.1007/s11356-021-15929-5.

Author contribution The conceptualization was from ZHL and WW. ZHL wrote and designed the manuscript. WML and YC collected background information and relevant literature. ZHL and GZL completed Table 1 and Table S2. ASY and WW read and corrected the contents.

Data availability Not applicable.

\section{Declarations}

Ethics approval and consent to participate Not applicable.

Consent for publication All of the authors agreed to publish the manuscript.

Competing interests The authors declare no competing interests.

\section{References}

Abdelhafez E, Dabbour L, Hamdan M (2021) The effect of weather data on the spread of COVID-19 in Jordan. Environ Sci Pollut Res Int:18

Adnan S, Hanif M, Khan AH, Latif M, Ullah K, Bashir F, Kamil S, Haider S (2021) Impact of heat index and ultraviolet index on COVID-19 in major cities of Pakistan. J Occup Environ Med 63: 98-103

Aidoo EN, Adebanji AO, Awashie GE, Appiah SK (2021) The effects of weather on the spread of COVID-19: evidence from Ghana. Bull Natl Res Cent 45:20

Al-Rousan N, Al-Najjar H (2020) The correlation between the spread of COVID-19 infections and weather variables in 30 Chinese provinces and the impact of Chinese government mitigation plans. Eur Rev Med Pharmacol Sci 24:4565-4571

Awasthi A, Sharma A, Kaur P, Gugamsetty B, Kumar A (2020) Statistical interpretation of environmental influencing parameters on COVID-19 during the lockdown in Delhi, India. Environ Dev Sustain:1-14

Bai X-H, Peng C, Jiang T, Hu Z-M, Huang D-S, Guan P (2019) Distribution of geographical scale, data aggregation unit and period in the correlation analysis between temperature and incidence of HFRS in mainland China: a systematic review of 27 ecological studies. PLoS Negl Trop Dis 13:e007688

Balshem H, Helfand M, Schünemann HJ, Oxman AD, Kunz R, Brozek J, Vist GE, Falck-Ytter Y, Meerpohl J, Norris S, Guyatt GH (2011) GRADE guidelines: 3. Rating the quality of evidence. J Clin Epidemiol 64:401-406

Byass P (2020) Eco-epidemiological assessment of the COVID-19 epidemic in China, January-February 2020. Glob Health Action 13: 1760490

Casanova LM, Jeon S, Rutala WA, Weber DJ, Sobsey MD (2010) Effects of air temperature and relative humidity on coronavirus survival on surfaces. Appl Environ Microbiol 76:2712-2717

Chen B, Liang H, Yuan X, Hu Y, Xu M, Zhao Y, Zhang B, Tian F, Zhu X (2020) Predicting the local COVID-19 outbreak around the world with meteorological conditions: a model-based qualitative study. BMJ Open 10:e041397

Cui X-X, Mou J-B, Teng Z, Zhou Y-Q, Fang F-H, Chen H-Y, Jiang H, Li H-S, Zhang X (2021) Study on stability of SARS-CoV-2 at different tempratures. Shanghai Municipal Center for Disease Control and Prevention, pp 1-7

Cumpston M, Li T, Page MJ, Chandler J, Welch VA, Higgins JP, Thomas J (2019) Updated guidance for trusted systematic reviews: a new edition of the Cochrane Handbook for Systematic Reviews of Interventions. Cochrane Database Syst Rev 10:ED000142 
Diao Y, Kodera S, Anzai D, Gomez-Tames J, Rashed EA, Hirata A (2021) Influence of population density, temperature, and absolute humidity on spread and decay durations of COVID-19: a comparative study of scenarios in China, England, Germany, and Japan. One Health 12:100203

Doğan B, Ben Jebli M, Shahzad K, Farooq TH, Shahzad U (2020) Investigating the effects of meteorological parameters on COVID19: case study of New Jersey, United States. Environ Res 191: 110148

Dong E, Du H, Gardner L (2020) An interactive web-based dashboard to track COVID-19 in real time. Lancet Infect Dis 20:533-534

Fan JL, Da YB, Zeng B, Zhang H, Liu Z, Jia N, Liu J, Wang B, Li LL, Guan DB, Zhang X (2021) How do weather and climate change impact the COVID-19 pandemic? Evidence from the Chinese mainland. Environ Res Lett 16:11

Fu S, Wang B, Zhou J, Xu X, Liu J, Ma Y, Li L, He X, Li S, Niu J, Luo B, Zhang K (2021) Meteorological factors, governmental responses and COVID-19: evidence from four European countries. Environ Res 194:110596

Guo C, Bo Y, Lin C, Li HB, Zeng Y, Zhang Y, Hossain MS, Chan JWM, Yeung DW, Kwok KO, Wong SYS, Lau AKH, Lao XQ (2021) Meteorological factors and COVID-19 incidence in 190 countries: an observational study. Sci Total Environ 757:143783

He Z, Chin Y, Yu S, Huang J, Zhang CJP, Zhu K, Azarakhsh N, Sheng J, He Y, Jayavanth P, Liu Q, Akinwunmi BO, Ming WK (2021) The influence of average temperature and relative humidity on new cases of COVID-19: time-series analysis. JMIR Public Health Surveill 7: e20495

Hoang T, Tran TTA (2021) Ambient air pollution, meteorology, and COVID-19 infection in Korea. J Med Virol 93:878-885

Hossain MS, Ahmed S, Uddin MJ (2021) Impact of weather on COVID19 transmission in south Asian countries: an application of the ARIMAX model. Sci Total Environ 761:143315

Huang H, Liang X, Huang J, Yuan Z, Ouyang H, Wei Y, Bai X (2020) Correlations between meteorological indicators, air quality and the COVID-19 pandemic in 12 cities across China. J Environ Health Sci Eng 18:1-8

Inagaki H, Saito A, Sugiyama H, Okabayashi T, Fujimoto S (2020) Rapid inactivation of SARS-CoV-2 with deep-UV LED irradiation. Emerg Microbes Infect 9:1744-1747

Iqbal N, Fareed Z, Shahzad F, He X, Shahzad U, Lina M (2020) The nexus between COVID-19, temperature and exchange rate in Wuhan city: new findings from partial and multiple wavelet coherence. Sci Total Environ 729:138916

Islam A, Hasanuzzaman M, Azad MAK, Salam R, Toshi FZ, Khan MSI, Alam GMM, Ibrahim SM (2020) Effect of meteorological factors on COVID-19 cases in Bangladesh. Environ Dev Sustain:1-24

Islam N, Bukhari Q, Jameel Y, Shabnam S, Erzurumluoglu AM, Siddique MA, Massaro JM, D'Agostino RB Sr (2021) COVID-19 and climatic factors: a global analysis. Environ Res 193:110355

Jamshidi S, Baniasad M, Niyogi D (2020) Global to USA county scale analysis of weather, urban density, mobility, homestay, and mask use on COVID-19. Int J Environ Res Public Health 17:7847

Jiang Y, Wu XJ, Guan YJ (2020) Effect of ambient air pollutants and meteorological variables on COVID-19 incidence. Infect Control Hosp Epidemiol 41:1011-1015

Kulkarni H, Khandait H, Narlawar UW, Rathod P, Mamtani M (2021) Independent association of meteorological characteristics with initial spread of Covid-19 in India. Sci Total Environ 764:142801

Kumar G, Kumar RR (2020) A correlation study between meteorological parameters and COVID-19 pandemic in Mumbai, India. Diabetes Metab Syndr 14:1735-1742

Kumar A, Misra S, Verma V, Vishwakarma RK, Kamal VK, Nath M, Prakash K, Upadhyay AD, Sahu JK (2020) Global impact of environmental temperature and $\mathrm{BCG}$ vaccination coverage on the transmissibility and fatality rate of COVID-19. PLoS One 15:e240710
Ladha N, Bhardwaj P, Charan J, Mitra P, Goyal JP, Sharma P, Singh K, Misra S (2020) Association of environmental parameters with COVID-19 in Delhi, India. Indian J Clin Biochem 35:1-5

Lasisi TT, Eluwole KK (2021) Is the weather-induced COVID-19 spread hypothesis a myth or reality? Evidence from the Russian Federation. Environ Sci Pollut Res Int 28:4840-4844

Li H, Xu XL, Dai DW, Huang ZY, Ma Z, Guan YJ (2020) Air pollution and temperature are associated with increased COVID-19 incidence: a time series study. Int J Infect Dis 97:278-282

Liu J, Zhou J, Yao J, Zhang X, Li L, Xu X, He X, Wang B, Fu S, Niu T, Yan J, Shi Y, Ren X, Niu J, Zhu W, Li S, Luo B, Zhang K (2020) Impact of meteorological factors on the COVID-19 transmission: a multi-city study in China. Sci Total Environ 726:138513

Malki Z, Atlam ES, Hassanien AE, Dagnew G, Elhosseini MA, Gad I (2020) Association between weather data and COVID-19 pandemic predicting mortality rate: machine learning approaches. Chaos, Solitons Fractals 138:110137

Martorell-Marugán J, Villatoro-García JA, García-Moreno A, LópezDomínguez R, Requena F, Merelo JJ, Lacasaña M, de Dios LJ, Díaz-Mochón JJ, Lorente JA, Carmona-Sáez P (2021) DatAC: A visual analytics platform to explore climate and air quality indicators associated with the COVID-19 pandemic in Spain. Sci Total Environ 750:141424

Mecenas P, Bastos RTRM, Vallinoto ACR, Normando D (2020) Effects of temperature and humidity on the spread of COVID-19: a systematic review. PLoS One 15:e238339

Mehmood K, Bao Y, Abrar MM, Petropoulos GP, Saifullah SA, Saud S, Khan ZA, Khan SM, Fahad S (2021) Spatiotemporal variability of COVID-19 pandemic in relation to air pollution, climate and socioeconomic factors in Pakistan. Chemosphere 271:129584

Menebo MM (2020) Temperature and precipitation associate with Covid19 new daily cases: a correlation study between weather and Covid19 pandemic in Oslo, Norway. Sci Total Environ 737:139659

Meo SA, Abukhalaf AA, Alomar AA, Al-Beeshi IZ, Alhowikan A, Shafi KM, Meo AS, Usmani AM, Akram J (2020a) Climate and COVID19 pandemic: effect of heat and humidity on the incidence and mortality in world's top ten hottest and top ten coldest countries. Eur Rev Med Pharmacol Sci 24:8232-8238

Meo SA, Abukhalaf AA, Alomar AA, Aljudi TW, Bajri HM, Sami W, Akram J, Akram SJ, Hajjar W (2020b) Impact of weather conditions on incidence and mortality of COVID-19 pandemic in Africa. Eur Rev Med Pharmacol Sci 24:9753-9759

Meo SA, Abukhalaf AA, Alomar AA, Sumaya OY, Sami W, Shafi KM, Meo AS, Usmani AM, Akram J (2020c) Effect of heat and humidity on the incidence and mortality due to COVID-19 pandemic in European countries. Eur Rev Med Pharmacol Sci 24:9216-9225

Meraj G, Farooq M, Singh SK, Romshoo SA, Sudhanshu, Nathawat MS, Kanga S (2020): Coronavirus pandemic versus temperature in the context of Indian subcontinent: a preliminary statistical analysis. Environ Dev Sustain, 1-11

Meyer A, Sadler R, Faverjon C, Cameron AR, Bannister-Tyrrell M (2020) Evidence that higher temperatures are associated with a marginally lower incidence of COVID-19 cases. Front Public Health 8: 367

Mo Z-F (2020) Dozens of infectious diseases fade with the seasons, what about COVID-19? Word Science No 497:29-32

Moher D, Liberati A, Tetzlaff J, Altman DG (2009) Preferred reporting items for systematic reviews and meta-analyses: the PRISMA statement. BMJ 339:b2535

Mozumder MSI, Amin MSA, Uddin MR, Talukder MJ (2021) Coronavirus COVID-19 outbreak and control: effect of temperature, relative humidity, and lockdown implementation. Arch Pediatr 28: $111-116$

Nakada LYK, Urban RC (2020) COVID-19 pandemic: environmental and social factors influencing the spread of SARS-CoV-2 in São Paulo, Brazil. Environ Sci Pollut Res Int:1-7 
Ogaugwu C, Mogaji H, Ogaugwu E, Nebo U, Okoh H, Agbo S, Agbon A (2020) Effect of weather on COVID-19 transmission and mortality in Lagos, Nigeria. Scientifica (Cairo) 2020:2562641

Ozyigit A (2020) Understanding Covid-19 transmission: the effect of temperature and health behavior on transmission rates. Infect Dis Health 25:233-238

Pahuja S, Madan M, Mittal S, Pandey RM, Nilima MK, Mohan A, Hadda V, Tiwari P, Guleria R (2021) Weather parameters and COVID-19: a correlational analysis. J Occup Environ Med 63:69-73

Pani SK, Lin NH, RavindraBabu S (2020) Association of COVID-19 pandemic with meteorological parameters over Singapore. Sci Total Environ 740:140112

Rashed EA, Kodera S, Gomez-Tames J, Hirata A (2020) Influence of absolute humidity, temperature and population density on COVID19 spread and decay durations: multi-prefecture study in Japan. Int J Environ Res Public Health 17:5354

Rendana M (2020) Impact of the wind conditions on COVID-19 pandemic: a new insight for direction of the spread of the virus. Urban Clim 34:100680

Rouen A, Adda J, Roy O, Rogers E, Lévy P (2020) COVID-19: relationship between atmospheric temperature and daily new cases growth rate. Epidemiol Infect 148:e184

Sahoo PK, Mangla S, Pathak AK, Salãmao GN, Sarkar D (2021) Pre-topost lockdown impact on air quality and the role of environmental factors in spreading the COVID-19 cases - a study from a worst-hit state of India. Int J Biometeorol 65:205-222

Sarkodie SA, Owusu PA (2020) Impact of meteorological factors on COVID-19 pandemic: evidence from top 20 countries with confirmed cases. Environ Res 191:110101

Shahzad F, Shahzad U, Fareed Z, Iqbal N, Hashmi SH, Ahmad F (2020) Asymmetric nexus between temperature and COVID-19 in the top ten affected provinces of China: a current application of quantile-onquantile approach. Sci Total Environ 736:139115

Shao W, Xie J, Zhu Y (2021) Mediation by human mobility of the association between temperature and COVID-19 transmission rate. Environ Res 194:110608

Sharif N, Dey SK (2021) Impact of population density and weather on COVID-19 pandemic and SARS-CoV-2 mutation frequency in Bangladesh. Epidemiol Infect 149:e16

Sharma P, Singh AK, Agrawal B, Sharma A (2020): Correlation between weather and COVID-19 pandemic in India: an empirical investigation. J Public Aff, e2222

Shi P, Dong Y, Yan H, Zhao C, Li X, Liu W, He M, Tang S, Xi S (2020) Impact of temperature on the dynamics of the COVID-19 outbreak in China. Sci Total Environ 728:138890

Singh O, Bhardwaj P, Kumar D (2020) Association between climatic variables and COVID-19 pandemic in National Capital Territory of Delhi, India. Environ Dev Sustain:1-15

Srivastava A (2021) COVID-19 and air pollution and meteorology-an intricate relationship: a review. Chemosphere 263:128297-128306

Tang L, Liu M, Ren B, Wu Z, Yu X, Peng C, Tian J (2021) Sunlight ultraviolet radiation dose is negatively correlated with the percent positive of SARS-CoV-2 and four other common human coronaviruses in the U.S. Sci Total Environ 751:141816

Tello-Leal E, Macías-Hernández BA (2020): Association of environmental and meteorological factors on the spread of COVID-19 in Victoria, Mexico, and air quality during the lockdown. Environ Res, 110442

Thangariyal S, Rastogi A, Tomar A, Bhadoria A, Baweja S (2020): Impact of temperature and sunshine duration on daily new cases and death due to COVID-19. medRxiv, 2020.06.13.20130138

To T, Zhang K, Maguire B, Terebessy E, Fong I, Parikh S, Zhu J (2021a) Correlation of ambient temperature and COVID-19 incidence in Canada. Sci Total Environ 750:141484

To T, Zhang K, Maguire B, Terebessy E, Fong I, Parikh S, Zhu J, Su Y (2021b) UV, ozone, and COVID-19 transmission in Ontario, Canada using generalised linear models. Environ Res 194:110645

Valente MJ, Pelham WE, Smyth H, MacKinnon DP (2017) Confounding in statistical mediation analysis: what it is and how to address it. J Couns Psychol 64:659-671

van Doremalen N, Bushmaker T, Munster VJ (2013) Stability of Middle East respiratory syndrome coronavirus (MERS-CoV) under different environmental conditions. Euro Surveill 18:20590-20593

Wang N, Mengersen K, Kimlin M, Zhou M, Tong S, Fang L, Wang B, $\mathrm{Hu}$ W (2018) Lung cancer and particulate pollution: a critical review of spatial and temporal analysis evidence. Environ Res 164:585-596

Wang H, Di B, Lin Q-X, Chen C, Li T-G (2020a) The short-term impact of meteorological factors on the transmission of COVID-19 in Guangzhou. J Trop Med 20:1226-1231

Wang Y, Liang D-Y, Li K, Zhang H-W, Fan W-H, Wu F-C (2020b) Preliminary study on environmental and climatic characteristics of historical infectious diseases and some thoughts of COVID-19. Res Environ Sci 33:1555-1561

Xie J, Zhu Y (2020) Association between ambient temperature and COVID-19 infection in 122 cities from China. Sci Total Environ 724:138201

Yang X-D, Li H-L, Cao Y-E (2021) Influence of meteorological factors on the COVID-19 transmission with season and geographic location. Int J Environ Res Public Health 18:484-496

Yuan J, Wu Y, Jing W, Liu J, Du M, Wang Y, Liu M (2021) Non-linear correlation between daily new cases of COVID-19 and meteorological factors in 127 countries. Environ Res 193:110521

Zhang N, Zhou H, Huang D-S, Guan P (2019) Brucellosis awareness and knowledge in communities worldwide: a systematic review and meta-analysis of 79 observational studies. PLoS Negl Trop Dis 13: e0007366-e0007366

Zhang C, Liao H, Strobl E, Li H, Li R, Jensen SS, Zhang Y (2021) The role of weather conditions in COVID-19 transmission: a study of a global panel of 1236 regions. J Clean Prod 292:125987

Publisher's note Springer Nature remains neutral with regard to jurisdictional claims in published maps and institutional affiliations. 